\title{
EDUKASI TB PARU PENGETAHUAN SIKAP KADER POSYANDU MELALUI PERMAINAN SIMULASI MONOPOLI
}

\section{PULMONARY TB EDUCATION ON KNOWLEDGE AND ATTITUDE OF POSYANDU CA- DRE THROUGH SIMULATION GAME OF MONOPOLY}

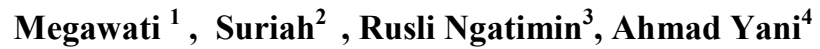 \\ 1,2,3 Departemen Promosi Kesehatan dan Ilmu Perilaku FKM UNHAS \\ ${ }^{4}$ Departemen Promosi Kesehatan dan Ilmu Perilaku FKM UNISMUH PALU \\ Email Korespondensi : \\ megawati09121981@gmail.com \\ suriah_74@yahoo.com
}

\begin{abstract}
Abstrak
Upaya yang bersumber dari masyarakat umumnya memperkuat tenaga kesehatan sehingga masyarakat juga dapat dilibatkan dalam meningkatkan pengetahuan tentang kasus TB paru, salah satunya adalah melalui kader posyandu. Penelitian bertujuan mengetahui perbedaan pengetahuan dan sikap TB paru melalui permainan simulasi monopoli TB. Penelitian menggunakan desain eksperimen semu, yaitu One Group Time Series. Populasi penelitian semua posyandu 70 kader. Penentuan sampel metode purposive sampling sebanyak 35 kader. Data dianalisis uji paired sampel $T$ test dengan taraf signifikan 0,05. Analisis dari pengetahuan menunjukkan perbedaan signifikan $\mathrm{T}_{\text {hitung }}=15,355>\mathrm{T}_{\text {tabel }}=1,6909$ dan $\mathrm{p}<0,05$, dan sikap menunjukkan perbedaan signifikan $\mathrm{T}_{\text {hitung }}=3,228>\mathrm{T}_{\text {tabel }}=1,6909$ dan $\mathrm{p}<0,05$ masing-masing pengukuran satu minggu sebelum dan sesudah intervensi. Pengetahuan terdapat perbedaan signifikan Thitung $=-16,199>\mathrm{T}_{\text {tabel }}=1,6909$ dan $\mathrm{p}<0,05$, sikap terdapat perbedaan signifikan $\mathrm{T}_{\text {hitung }}=-3,228>\mathrm{T}_{\text {tabel }}=1,909$ dan $\mathrm{p}<0,05$ masing- masing satu minggu sebelum intervensi dan satu bulan sesudah intervensi. Pengetahuan ada perbedaan tidak signifikan $T_{\text {hitung }}=-1,785<T_{\text {tabel }}=1,6909$ dan $p>0,05$, sikap ada perbedaan tidak signifikan $T_{\text {hitung }}$ $1,694<\mathrm{T}_{\text {tabel }}=1,6909$ dan $\mathrm{p}>0,05$, masing-masing pengukuran satu minggu dan satu bulan sesudah intervensi. Terdapat perubahan pengetahuan dan sikap dengan media permainan simulasi monopoli TB kepada kader posyandu puskesmas Bangkir Kab Tolitoli.
\end{abstract}

Kata Kunci : Edukasi, simulasi monopoli, pengetahuan, sikap

\begin{abstract}
The effort stems from the community generally strengthen the health workforce so that the community can also be involved in improving the knowledge of pulmonary TB cases, one of which is through posyandu cadre. The research aims to find out the difference of pulmonary TB knowledge and attitude through a simulation game in monopolistic TB. The research uses quasi experimental design, i.e. One Group Time Series. Population research all posyandu 70 cadres. Determination of purposive sampling method sampling as much as 35 cadres. The data analyzed test paired samples $T$ test with significant degrees of 0.05 . Analysis of knowledge shows significant differences $T_{\text {hitung }}=T_{\text {tabel }}=1,6909>15,355$ and $p<0,05$, and shows significant differences $T_{\text {hitung }}=-3,228>T_{\text {tabel }}=1,6909$ and $p<0,05$ each measurement one week before and after the intervention. There are significant differences of knowledge measurement $T_{\text {hitung }}=-T_{\text {tabel }}=1,6909>16,199$ and $p<0,05$, there are significant differences in attitude measurement $T_{\text {hitung }}=-3,228>T_{\text {tabel }}=p$ and 1,909<0,05 each one week prior to the intervention and one month after the intervention. Knowledge there was not significant difference $T_{\text {hitung }}=-1,785<1,6909$ and $p=T_{\text {tabel }}>0,05$, the measurement of attitudes there are insignificant differences 1,694 $T_{\text {hitung }}<1,6909$ and $p=T_{\text {tabel }}>0,05$ each measurement one week and one month after the intervention. There are changes in knowledge and attitude with the media simulation game monopoly posyandu cadre to TB. There are changes in knowledge and attitude with the media simulation game Monopoly posyandu cadre to TB Clinics Bangkir Kab of Tolitoli
\end{abstract}

Keywords: Elderly, hypertension, waist circumference, hip circumference, BMI 


\section{PENDAHULUAN}

Tuberculosis (TB) adalah suatu penyakit infeksi menular yang disebabkan oleh bakteri Mycobacterium Tuberculosis, yang dapat menyerang berbagai organ terutama paru-paru. Penyakit ini bila tidak diobati atau pengobatannya tidak tuntas dapat menimbulkan komplikasi berbahaya hingga kematian. ${ }^{1}$

Menurut organisasi kesehatan dunia (WHO), sepertiga populasi dunia diperkirakan terinfeksi Mycobacterium Tuberculosis. Pada tahun 1992 WHO telah menetapkan Tuberculosis sebagai kedaruratan global. Menurut laporan global Tuberculosis WHO tahun 2015 diperkirakan ada $^{9,6}$ juta kasus baru TB di dunia dan 1,5 juta orang meninggal karena TB. Asia Tenggara dan Pasifik Barat menyumbang 58\% dari kasus TB di dunia pada tahun 2014. Prevalensi TB di Indonesia dan negaranegara berkembang lainnya cukup tinggi. Indonesia menempati posisi tiga besar negara dengan jumlah kasus Tuberculosis terbanyak bersama India dan Cina. ${ }^{2}$

Berdasarkan profil data kesehatan Indonesia pada tahun 2014, jumlah kasus baru TB paru BTA positif di seluruh propinsi di Indonesia sebanyak 176.677 kasus. Menurun bila dibandingkan kasus baru BTA positif yang ditemukan tahun 2013 yang sebesar 196.310 kasus. Jumlah kasus tertinggi yang dilaporkan terdapat di propinsi dengan jumlah penduduk yang besar yaitu Jawa Barat, Jawa Timur, dan Jawa Tengah. Kasus baru BTA positif di tiga propinsi tersebut sebesar $40 \%$ dari jumlah seluruh kasus baru di Indonesia.1 Menurut jenis kelamin, kasus BTA positif pada laki-laki lebih tinggi dari pada perempuan yaitu 1,5 kali. Pada masing-masing propinsi di seluruh Indonesia kasus BTA positif lebih banyak terjadi pada laki-laki dibandingkan perempuan. Disparitas paling tinggi antara laki-laki dan perempuan terjadi di Kepulauan Bangka Belitung. Sementara di Provinsi Sulawesi Tengah, hasil penemuan kasus baru yang cukup signifikan dari tahun 2010 dengan jumlah kasus 2.719, meningkat menjadi 3.206 kasus pada tahun 2011. Pada tahun 2012 jumlah kasus baru TB paru BTA positif yang ditemukan sebanyak 3.324 kasus, ada peningkatan kasus pada tahun 2013 yakni 3.539 kasus meningkat lagi pada tahun 2014 yakni, 3.848 kasus. ${ }^{3}$

Pemberantasan tuberkulosis paru di Kabupaten Tolitoli dilakukan di 14 Puskesmas melalui program DOTS. Tercatat dengan jumlah penemuan penderita TB paru BTA positif pada tahun 2013 laki-laki sebanyak 223 kasus, perempuan 136 kasus jumlah keseluruhan penderita TB paru BTA positif yaitu 359 kasus. Tahun 2014 jumlah penderita TB paru BTA positif pada lakilaki sebanyak 196 kasus perempuan 127 kasus yang jumlah keseluruhan 396 kasus, sedangkan pada tahun 2015 penderita TB paru BTA positif pada laki-laki 185 kasus dan perempuan 125 kasus yang jumlahnya 310 kasus, jumlah keseluruhan penderita TB paru BTA positif sebanyak 992 kasus. $^{4}$

Puskesmas Bangkir sebagai salah satu wilayah kerja Kabupaten Tolitoli, menunjukkan penemuan penderita TB paru BTA positif pada tahun 2013 yakni, laki-laki 6 kasus perempuan 2 kasus. Pada tahun 2014 laki-laki 6 kasus perempuan 2 kasus, sedangkan pada tahun 2015 penderita TB paru BTA positif yang ditemukan pada laki-laki 1 kasus dan perempuan nihil. Jumlah keseluruhan penderita TB paru BTA positif dari tahun 2013 s/d 2015 sebanyak 17 kasus. Prevalensi penderita TB paru yang meninggal pada tahun $2013 \mathrm{~s} / \mathrm{d}$ 2015 adalah 5 kasus yang rinciannya, pada laki-laki 3 kasus sedangkan perempuan 2 kasus. ${ }^{5}$

Rendahnya angka penemuan kasus TB dapat disebabkan oleh berbagai faktor, diantaranya adalah sistim surveilance yang belum kuat, kemampuan mendiagnosa penyakit TB yang kurang, disertai kurangnya akses ke pelayanan kesehatan. ${ }^{6}$ Kurangnya pengetahuan masyarakat tentang gejala-gejala awal TB paru dan sistem penjaringan penderita di puskesmas dalam melakukan anamnesa yang belum optimal, kurang terbukanya masyarakat mengenai penyakit TB karena dianggapnya sebagai penyakit keturunan dan masyarakat enggan memeriksakan diri karena rasa malu. ${ }^{6}$

Upaya untuk meningkatkan pengetahuan tentang TB dapat dilakukan oleh masyarakat dan semua tenaga kesahatan. $^{7}$ Upaya untuk meningkatkan pengetahuan dan sikap tentang $\mathrm{TB}$ di masyarakat dalam rangka meningkatkan kesehatan masyarakat termasuk memperkuat peran kader. Salah satunya melalui edukasi kepada kader tentang TB paru. Model deteksi dini TB paru oleh kader ini konsisten dengan salah satu elemen dalam Stop TB Partnership untuk menghentikan TB yaitu pemberdayaan kader dan komunitas sehingga dapat mengurangi ketergantungan masyarakat kepada petugas kesehatan untuk memecahkan masalah kesehatan mereka. Berdasarkan penjelasan diatas peneliti ingin melakukan penelitian tentang Edukasi TB Paru Tentang Pengetahuan dan Sikap Kader Melalui Permainan Simulasi Monopoli TB di Wilayah Puskesmas Bangkir.

\section{METODE}

Penelitian ini merupakan penelitian eksperimen semu dengan menggunakan rancangan One Group Time Series. ${ }^{8}$ Penelitian ini dilaksanakan di aula Desa Bangkir Kecamatan Dampal Selatan Kabupaten Tolitoli pada tanggal 12 Februari-19 Maret 2017. Adapun populasi dalam penelitian ini adalah 70 kader Posyandu di wilayah kerja Puskesmas Bangkir, Kecamatan Dampal Selatan, Kabupaten Tolitoli. Tehnik pengambilan sampel pada penelitian ini adalah purposive sampling. ${ }^{9}$ Teknik purposive didasarkan pada suatu pertimbangan tertentu, yaitu kader yang aktif, bisa baca tulis dan umur $>50$ tahun, sehingga peneliti mendapatkan sampel sejumlah 35 sampel dari 70 populasi yang ada di wilayah kerja Puskesmas Bangkir Kabupaten Tolitoli. Data dikumpulkan dengan cara pretes satu minggu sebelum intervensi, postest pertama satu minggu sesudah intervensi dan postest kedua satu bulan sesudah intervensi, dengan menggunakan instrumen kuesioner. Pengolahan data dilakukan dengan menggunakan program SPSS dan kemudian disajikan dalam bentuk tabel disertai dengan penjelasan dalam bentuk narasi.

\section{HASIL}

Penelitian ini mendapatkan distribusi karakteristik responden kelompok usia terbanyak terdapat pada 
kelompok umur antara 26-35 tahun yaitu 24 responden $(42,85 \%)$, sedangkan yang paling sedikit terdapat pada kelompok umur antara 46-55 tahun yaitu 4 responden $(17,14)$ dari 35 responden kader posyandu puskesmas Bangkir Kecamatan Dampal Selatan. Berdasarkan pendidikan terakhir responden diketahui pendidikan responden terbanyak adalah SMA 14 responden (40\%), Pendidikan SD dan SMP masing-masing 10 responden $(28,6)$, Sedangkan responden yang paling sedikit adalah Perguruan Tinggi (D3) 1 responden $(2,9 \%)$ dari 35 responden kader posyandu puskesmas Bangkir Kecamatan Dampal Selatan. Distribusi responden berdasarkan sumber informasi mengenai TB paru yang terbanyak di televisi yaitu 23 responden $(65,7 \%)$, informasi dari tetangga/kerabat 8 responden $(22,9 \%)$, sedangkan Sumbser informasi yang paling sedikit yaitu puskesmas 4 responden $(11,4 \%)$. dari 35 responden kader posyandu Puskesmas Bangkir Kecamatan Dampal Selatan. kader 11-30 tahun 6 responden $(17,14 \%)$, sedangkan responden lama jadi kader 6-1 tahun 2 responden $(5,7 \%)$, dari 35 responden kader posyandu puskesmas Bangkir Kecamatan Dampal. Distribusi responden berdasarkan pekerjaan diketahui bahwa pekerjaan responden sebagian besar IRT (Ibu Rumah Tangga) yaitu 29 responden $(82,9 \%)$, pekerjaan sebagai petani 2 responden $(5,7 \%)$ dan pekerjaan responden sebagai pegawai swasta 4 responden $(11,4 \%)$, dari 35 responden kader posyandu puskesmas Bangkir Kecamatan Dampal Selatan.

Pada tabel 2 nampak pengukuran antar waktu didapatkan bahwa pengetahuan responden sebelum intervensi dengan menggunakan permainan simulasi monopoli TB, pada pengukuran pretest yang dilakukan dari 35 responden didapatkan skor tertinggi yakni 33 dan skor terendah $22(\mathrm{M}=28,11 ; \mathrm{SD}=28,57 ; \mathrm{R}=11)$. Pengukuran postest pertama pengetahuan yang dilakukan

\section{Tabel 1. Distribusi Berdasarkan Karakteristik Responden Wilayah Puskesmas Bangkir Kecamatan Dampal Selatan Kabupaten Tolitoli}

\begin{tabular}{|c|c|c|}
\hline Karakteristik Responden & Frekuensi (n) & Persentase (\%) \\
\hline \multicolumn{3}{|l|}{ Umur (Tahun) } \\
\hline $\begin{array}{l}26-35 \\
46-45\end{array}$ & $\begin{array}{l}15 \\
14\end{array}$ & $\begin{array}{c}42,85 \\
40\end{array}$ \\
\hline $46-55$ & 6 & 17,14 \\
\hline \multicolumn{3}{|l|}{ Tingkat Pendidikan } \\
\hline SD & 10 & 28,6 \\
\hline SMP & 10 & 28,6 \\
\hline SMA & 14 & 40 \\
\hline D3 & 1 & 2,9 \\
\hline \multicolumn{3}{|l|}{ Sumber Informasi } \\
\hline & 23 & 65,7 \\
\hline Puskesmas & 4 & 11,4 \\
\hline Tetangga/Kerabat & 8 & 22,9 \\
\hline \multicolumn{3}{|l|}{ Lama Jadi Kader (Tahun) } \\
\hline $6-1$ & 2 & 5,4 \\
\hline $2-10$ & 27 & 77,4 \\
\hline $11-30$ & 6 & 17,14 \\
\hline \multicolumn{3}{|l|}{ Pekerjaan } \\
\hline Ibu Rumah Tangga (IRT) & 29 & 82,9 \\
\hline Petani & 2 & 5,7 \\
\hline Pegawai Swasta & 4 & 11,4 \\
\hline
\end{tabular}

Sumber: Data Primer, 2017

Distribusi lama jadi kader yaitu sebagian besar kader yang sudah lama menjadi kader 1-10 tahun yaitu 27 responden $(77,4 \%)$, responden dengan lama jadi dari 35 responden didapatkan skor tertinggi yakni 36 dan skor terendah $31(\mathrm{M}=35,51 ; \mathrm{SD}=1,095 ; \mathrm{R}=5)$. Pen- 
gukuran postest kedua, jawaban responden dengan skor tertinggi 36 dan skor terendah $34(\mathrm{M}=35,77 ; \mathrm{SD}=547$; $\mathrm{R}=12$ ). Untuk pernyataan sikap pengukuran pretest skor tertinggi yaitu 45 dan skor $26 \quad(M=37,09$; $\mathrm{SD}=3,944 ; \mathrm{R}=19)$. Untuk sikap pengukuran postest pertama skor tertinggi yaitu 47 dan skor terendah 35 $(\mathrm{M}=42,37 ; \mathrm{SD}=3,191 ; \mathrm{R}=12)$, serta pengukuran postest kedua skor tertinggi 47 dan skor terendah $37(\mathrm{M}=42,83$; $\mathrm{SD}=2,915 ; \mathrm{R}=10$ ). Berdasarkan hasil analisis bivariat pada penelitian ini dilakukan dengan uji Paired Sample $T$ Test dengan menggunakan program SPSS. Analisis bivariat digunakan untuk mendapatkan gambaran perbedaan tiap-tiap variabel penelitian baik sebelum intervensi maupun sesudah intervensi. satu minggu sesudah intervensi menggunakan uji Paired Samples T Tes. Mendapatkan hasil bahwa pengetahuan responden pada satu minggu sebelum intervensi didapatkan rata-rata nilai skor pada pretest sebesar 28,11 , sedangkan pengetahuan setelah satu minggu dilakukan intervensi terdapat ratarata skor sebesar 35,51 dengan korelasi 0,197 dan beda selisi rata-rata $-7,400$, sehingga dapat dikatakan ada perbedaan signifikan pengetahuan setelah intervensi (pengetahuan responden pada nilai rerata postest lebih tinggi dibandingkan rerata pretest) kemaknaan ini dapat dilihat pada $T_{\text {hitung }}=15,355$ $>\mathrm{T}_{\text {tabel }}=1,6909$ dan $\mathrm{p}<0,05$. Sama halnya dengan sikap didapatkan rata-rata nilai skor pada pretest sebesar 37,09 dan postest pertama didapatkan skor rata-rata 42,37 dengan korelasi 0,449 selisih beda nilai rata-rata antara

Tabel 2. Distribusi Berdasarkan Karakteristik Responden Wilayah Puskesmas Bangkir

\begin{tabular}{|c|c|c|c|c|c|c|}
\hline \multirow{2}{*}{ Variabel } & \multicolumn{6}{|c|}{ Perlakuan } \\
\hline & $\mathbf{n}$ & Mean & SD & Range & Min & $\operatorname{Max}$ \\
\hline $\begin{array}{l}\text { Pengetahuan } 1 \\
\text { Minggu Sebelum } \\
\text { Perlakuan }\end{array}$ & 35 & 28,11 & 28,57 & 11 & 22 & 33 \\
\hline $\begin{array}{l}\text { Pengetahuan } 1 \\
\text { Minggu Sesudah } \\
\text { Intervensi }\end{array}$ & 35 & 35,51 & 1,095 & 5 & 31 & 36 \\
\hline Pengetahuan 1 Bulan Sesudah Intervensi & 35 & 35,77 & 0,547 & 2 & 34 & 36 \\
\hline $\begin{array}{c}\text { Sikap } 1 \text { Sebelum I } \\
\text { ntervensi }\end{array}$ & 35 & 37,09 & 3,944 & 19 & 26 & 45 \\
\hline Sikap 1 minggu Sesudah Intervensi & 35 & 42,37 & 3,191 & 12 & 35 & 47 \\
\hline $\begin{array}{l}\text { Sikap } 1 \text { Bulan Sesudah } \\
\text { Intervensi }\end{array}$ & 35 & 42,83 & 2,915 & 10 & 57 & 47 \\
\hline
\end{tabular}

Sumber: Data Primer, 2017

Tabel 3. Perbedaan Pengetahuan dengan Sikap tentang TB paru Satu Minggu Sebelum Intervensi dan Satu Minggu sesudah Intervensi

\begin{tabular}{|c|c|c|c|c|c|c|c|c|}
\hline \multirow[t]{2}{*}{ Variabel } & & \multicolumn{2}{|c|}{$\begin{array}{l}\text { Paired } \\
\text { Samples } \\
\text { Statistik }\end{array}$} & \multirow{2}{*}{$\begin{array}{l}\text { Paired } \\
\text { Samples } \\
\text { Crelation }\end{array}$} & \multicolumn{4}{|c|}{ Paired Samples Test } \\
\hline & & Mean & SD & & DF & $\mathbf{T}$ & Mean & P Value \\
\hline Pengetahuan & $\begin{array}{l}\text { Pretest1 } \\
\text { Postest } 1\end{array}$ & $\begin{array}{l}28,11 \\
35,51\end{array}$ & $\begin{array}{l}2,857 \\
0,547\end{array}$ & 0,197 & 34 & $-15,355$ & $-7,400$ & 0,000 \\
\hline Sikap & Postest 1 & 37,09 & 3,944 & 0,449 & 34 & $-3,228$ & $-5,286$ & 0,000 \\
\hline
\end{tabular}

Sumber: Data Primer, 2017

Pada tabel 3 terlihat Nilai perbedaan variabel pengetahuan dan sikap satu minggu sebelum intervensi dan pretes dan postest pertama adalah sebesar $-5,286$, artinya 
sikap responden pada postest pertama lebih tinggi dibandingkan rerata pretest, perbedaan ini dapat dilihat pada $T_{\text {hitung }}=-3,228>T_{\text {tabel }}=1,6909$ dan $\mathrm{p}<0,05$.

Tabel 4 menunjukkan Nilai perbedaan variabel pengetahuan dan sikap satu minggu sebelum intervensi dan satu bulan sesudah intervensi menggunakan uji Paired samples T Tes. mendapatkan hasil bahwa pengetahuan responden pada satu minggu sebelum intervensi didapatkan rata-rata nilai skor pada pretest sebesar 28,11 , sedangkan pengetahuan setelah satu bulan dilakukan intervensi terdapat ratarata skor sebesar 35,77 dengan korelasi 0,205 , perbedaan selisih rata-rata sebesar -7,657 yang artinya pengetahuan responden pada nilai rerata postes kedua lebih tinggi dibandingkan rerata pretest, hal ini dapat dilihat pada $\mathrm{T}_{\text {hitung }}=-16,199$ $>\mathrm{T}_{\text {tabel }}=1,6909$ dan $\mathrm{p}<0,05$. Sedangkan untuk sikap didapatkan nilai skor rata-rata satu minggu sebelum intervensi adalah 37,09, setelah dilakukan intervensi didapatkan skor rata-rata 42,83 dengan korelasi 0,349, yang artinya ada peningkatan signifikan sikap responden, hal ini dilihat pada $\mathrm{T}_{\text {hitung }}=-3,228>\mathrm{T}_{\text {tabel }}=1,6909$ dan $\mathrm{p}<0,05$.

Tabel 4. Perbedaan Pengetahuan dengan Sikap tentang TB paru Satu Minggu sebelum Intervensi dan Satu Bulan Sesudah Intervensi sesudah intervensi dan satu bulan intervensi menggunakan uji Paired Samples T Test, mendapatkan hasil bahwa pengetahuan responden pada satu minggu sesudah intervensi didapatkan rata-rata nilai skor pada postest pertama sebesar 35,51, sedangkan pengetahuan setelah satu bulan dilakukan intervensi terdapat rata-rata skor sebesar 35,77 dengan korelasi 0,644, artinya terjadi peningkatan tidak signifikan, hal ini dapat dilihat pada $\mathrm{T}_{\text {hitung }}=-1,785<\mathrm{T}_{\text {tabel }}=1,6909$ dan $\mathrm{p}>0$ 0,05. Sedangkan sikap responden pada satu minggu sesudah intervensi didapatkan rata-rata nilai skor 42,37, sedangkan sikap setelah satu bulan sesudah intervensi terdapat rata-rata 42,83 dengan korelasi 0,867 , artinya ada peningkatan tidak signifikan, hal ini dapat lihat pada $T_{\text {hi- }}$ tung $=1,694<\mathrm{T}_{\text {tabel }}=1,6909$ dan $\mathrm{p}>0,05$.

\section{PEMBAHASAN}

Pengetahuan merupakan hasil tahu dan ini terjadi setelah orang melakukan penginderaan terhadap suatu obyek tertentu. Penginderaan terjadi melalui panca indera manusia, yakni: indera penglihatan, pendengaran, penciuman, rasa dan raba. Sebagian besar pengetahuan manusia diperoleh melalui mata dan telinga. Penge-

\begin{tabular}{|c|c|c|c|c|c|c|c|c|}
\hline \multirow{2}{*}{\multicolumn{2}{|c|}{ Variabel }} & \multicolumn{2}{|c|}{$\begin{array}{c}\text { Paired Samples } \\
\text { Statistik }\end{array}$} & \multirow{2}{*}{$\begin{array}{c}\text { Paired } \\
\text { Samples } \\
\text { Crelation } \\
\text { Correlation } \\
\end{array}$} & \multicolumn{4}{|c|}{ Paired Samples Test } \\
\hline & & Mean & SD & & DF & $\mathbf{T}$ & Mean & p value \\
\hline & $\begin{array}{l}\text { Pretest } 1 \\
\text { Postest } 2 \\
\end{array}$ & & & & & & & \\
\hline Sikap & $\begin{array}{c}\text { Pretest } 1 \\
\text { Postest } 2\end{array}$ & $\begin{array}{l}37,09 \\
42,83\end{array}$ & $\begin{array}{l}3,944 \\
2,915\end{array}$ & 0,349 & 34 & $-8,488$ & $-5,743$ & 0,000 \\
\hline Pengetahuan & & $\begin{array}{l}28,11 \\
35,77\end{array}$ & $\begin{array}{l}2,857 \\
1.095\end{array}$ & 0,205 & 34 & $-16,199$ & $-7,657$ & 0,000 \\
\hline
\end{tabular}

Sumber: Data Primer, 2017

Tabel 5. Perbedaan Pengetahuan dengan Sikap tentang TB paru Satu Minggu sesudah Intervensi dan Satu Bulan Sesudah Intervensi

\begin{tabular}{|c|c|c|c|c|c|c|c|c|}
\hline \multicolumn{2}{|c|}{ Variabel } & \multicolumn{2}{|c|}{$\begin{array}{c}\text { Paired Samples } \\
\text { Statistik }\end{array}$} & \multirow{2}{*}{$\begin{array}{c}\text { Paired } \\
\text { Samples } \\
\text { Crelation } \\
\text { Correlation }\end{array}$} & \multicolumn{4}{|c|}{ Paired Samples Test } \\
\hline & & Mean & SD & & DF & $\mathbf{T}$ & Mean & p value \\
\hline Pengetahuan & $\begin{array}{l}\text { Postest } 1 \\
\text { Postest } 2\end{array}$ & $\begin{array}{l}35,51 \\
35,77\end{array}$ & $\begin{array}{l}1,095 \\
0,547\end{array}$ & 0,644 & 34 & $-1,785$ & $-2,57$ & 0,083 \\
\hline Sikap & $\begin{array}{l}\text { Postest } 1 \\
\text { Postest } 2\end{array}$ & $\begin{array}{l}42,37 \\
42,83\end{array}$ & $\begin{array}{l}3,191 \\
2,915\end{array}$ & 0,867 & 34 & $-1,694$ & $-4,57$ & 0,099 \\
\hline
\end{tabular}

\section{Sumber: Data Primer, 2017}

Sedangkan pada table 5 memperlihatkan nilai perbedaan variabel pengetahuan dan sikap satu minggu tahuan diharapkan dapat berpengaruh terhadap perilakunya. Dengan kata lain, dengan adanya pendidikan 
dapat membawa akibat terhadap perubahan perilaku sasaran. Untuk mencapai tujuan pendidikan yakni perubahan-perubahan perilaku dipengaruhi oleh beberapa faktor yaitu proses pendidikan, materi, pendidik dan alat bantu dalam proses pendidikan.

Berdasarkan hasil penelitian variabel pengetahuan dan sikap pada pengukuran pertama pretest satu minggu sebelum intervensi didapatkan hasil skoring rendah ini dikarenakan responden menjawab pertanyaan -pertanyaan apa yang diketahui selama ini. Setelah mendapatkan intervensi melalui permainan simulasi monopoli, kemudian melakukan pengukuran kedua postest pertama satu minggu sesudah intervensi didapatkan hasil perbedaan yang signifikan. Berdasarkan teori Notoatmodjo, bahwa pada tahap ini merupakan tahap tahu (know) yang diartikan hanya sebagai recall (memanggil) memori yang telah ada sebelumnya, sebelum mengamati sesuatu. ${ }^{6}$ Sehubungan dengan hal tersebut peneliti berasumsi bahwa intervensi dengan menggunakan media permainan simulasi monopoli TB dapat meningkatkan pengetahuan dan sikap kader posyandu.

Berdasarkan teori S-O-R (Stimulus Organisme Respon) yang dikemukakan oleh Effendy, bahwa teori ini berasal dari ilmu psikologi kemudian telah dikembangkan dalam ilmu komunikasi. Dalam teori ini terdiri dari tiga elemen Pesan (Stimuli, S), Penerima, O), Efek, (Respon, R) dimana maksud dari teori ini adalah menjelaskan pengaruh yang terjadi pada pihak penerima sebagai akibat dari komunikasi. Besar kecilnya pengaruh serta dalam bentuk apa pengaruh itu terjadi, tergantung pada isi penyajian stimulus. ${ }^{10}$ Penelitian ini sejalan dengan penelitian Widodo bahwa terdapat perbedaan pengetahuan dan sikap ibu-ibu PKK desa Pabelan antara sebelum dan sesudah perlakuan. Pengetahuan dan sikap ibu-ibu PKK desa Pabelan lebih baik setelah dilakukan promosi kesehatan. ${ }^{11}$ Penelitian ini diperkuat oleh penelitian Labilah, mereka memperlihatkan bahwa pendidikan kesehatan gigi dan mulut dengan alat permainan ular tangga memiliki pengarauh terhadap pengetahuan tentang kesehatan gigi dan mulut anak. $^{12}$

Perbandingan hasil skoring pengetahuan dan sikap pada pengukuran pertama pada pretest satu minggu sebelum intervensi dan pada pengukuran ketiga pada postest kedua satu bulan sesudah intervensi mendapatkan hasil perbedaan yang signifikan ini terjadi karena kemampuan responden mengingat dan mengolah pesan yang telah didapat sebelumnya. sebagaimana yang diungkapkan Arief dalam Wahyudin, bahwa hasil pengetahuan seseorang diperoleh dari pengalaman pendengaran $11 \%$, dari pengamatan penglihatan $83 \%$, sedangkan kemampuan daya ingat yaitu berupa pengalaman yang diperoleh dari apa yang didengar $20 \%$, dari pengalaman apa yang dilihat $50 \%{ }^{13}$

Penelitian ini diperkuat pula oleh penelitian Sukiarto, mengatakan pada skor rata-rata pada pretest $=63,10 \%$; simpan baku=10,89; selisih rerata $=17,05 ; \mathrm{t}=-9,841$, sedangkan skor rata-rata pada postest $=84.77 \%$; simpan baku $=9,67$; selisih rerata $=21,67 ; \mathrm{t}=-12,204$, artinya secara statistik menunjukkan adanya perbedaan yang signifikan $\mathrm{p}<0,05$, rerata skor keterampilan kader gizi kelompok BBM meningkat setelah mendapat pelatihan. Belajar Berdasarkan Masalah (BBM) antara pretes ke postes ${ }^{2.14}$ Penelitian ini sejalan pula dengan penelitian yang dilakukan oleh Hartati, mengatakan bahwa pelatihan kader dengan menggunakan permainan simulasi monopoli efektif meningkatkan kemampuan kader dalam penilaian status gizi balita. ${ }^{15}$

Pada hasil skoring pengetahuan dan sikap pada postest kedua satu minggu setelah intervensi dan postest ketiga satu bulan sesudah intervensi mendapatkan hasil ada perbedaan tidak signifikan ini terjadi karena responden sudah terpapar dengan pertanyaan-pertanyaan yang telah didapatkan sebelumnya pada pengukuran pertama dan kedua. Dan pada pengukuran ketiga pada postest kedua satu bulan setelah intervensi skor jawaban tidak berkurang karena pengetahuan dan sikap pada satu bulan responden masih dapat mengingat pesan yang telah diberikan. Hal ini selajan dengan hasil penelitian Sukiarto, mengatakan bahwa pada postes satu rerata $=62,80$; simpang baku=10,05; selisih rerata $=0,85 ; \mathrm{t}=-1,574$; $\mathrm{p}=0,125$, sedangkan postest rerata $=63,26$; simpang ba$\mathrm{ku}=10,06 ;$ selisih rerata $=1,29 ; \mathrm{t}=-1,366 ; \mathrm{p}=0,182$, artinya ada peningkatan tetapi tidak signifikan $(\mathrm{p}>0,05) .{ }^{15}$ Hasil penelitian ini sejalan pula dengan penelitian Darmin, mengatakan bahwa pengukuran pada postes 2 ke postest 3 ( $M D=324 ; p>0,05)$ terjadi peningkatan pengetahuan dan tidak signifikan. ${ }^{16}$

\section{KESIMPULAN DAN SARAN}

Berdasarkan hasil penelitian yang telah dilakukan pada kader poayandu Pusksemas Bangkir Kecamatan Dampal Selatan Kabupaten Tolitoli, maka dapat diambil kesimpulan bahwa pengetahuan dan sikap kader posyandu meningkat setelah mendapatkan intervensi permainan simulasi monopoli TB. Saran dalam penelitian ini adalah kepada pihak Dinas Kesehatan Kabupaten tolitoli hendaknya dapat mereplikasikan dan mengimplementasikan metode ini diseluruh Kabupaten Tolitoli. Selain itu dapat menjadi bahan kajian dalam menentukan kebijakan tentang peningkatan pengetahuan dan sikap kader dalam program terkait TB paru, sehingga masalah kesehatan yang ada di masyarakat dapat teratasi secara dini.

\section{DAFTAR PUSTAKA}

1. Kemenkes RI. Pedoman Nasional Pengendalian Tuberculosis. Kemenkes R1; 2014.

2. WHO. Global Tuberculosis Report. WHO/HTM/ TB/2015.22. Geneva:WHO Press; 2015. WHO. Judul. Geneva : World Health Organization; 2015.

3. Dinas Kesehatan Provinsi Sulawesi Tengah. Profil Kesehatan dan Pengelola P2PL. Palu. Provinsi Sulawesi Tengah; 2014.

4. Dinas Kesehatan Kab. Tolitoli. Profil Dinas Kesehatan Kabupaten Tolitoli. Tolitoli. Dinas Kesehatan Kab. Tolitoli; 2016.

5. Puskesmas Bangkir. Laporan Program dan Pelayanan Kesehatan Puskesmas Bangkir, Kec. Dampal Selatan Kabupaten Tolitoli. Bangkir. Puskesmas Bangkir; 2016. 
6. WHO.Global Tuberculosis Control: World Health Organization; 2011.

7. Notoatmodjo S. Promosi Kesehatan Teori dan Aplikasi. Jakarta: Reneka Cipta; 2010.

8. SaryonoMetode Penelitian Kuantitatif dan Kualitatif Dalam Bidang Kesehatan. Yogyakarta: Nuha Medika; 2013.

9. Sugiyono. Metode Penelitian Kualitatif Kuantitatif dan R \& D. Bandung: Alfabeta; 2008.

10. Effendy, O. U. Ilmu Teori dan Filsafat Komunikasi. Bandung: PT. Citra Aditya Bakti; 2003.

11. Setiyadi, N. A, Widodo, A. Promosi Perilaku Kesehatan Masyarakat untuk Mencegah Penyakit DBD dan TBC. Prosiding Seminar Ilmiah Nasional Kesehatan. 2013.

12. Labibah, A. A. Nurhapsari, R. Mujayanto. Pengaruh Permainan Ular Tangga Modifikasi Terhadap Pengetahuan Kesehatan Gigi Dan Mulut Pada Anak (Studi terhadap Siswa SD N 4 Tanggungharjo, Kecamatan Grobogan). Online Journal. 2015.

13. Isa, A. Keefektifan Pembelajaran Berbantuan Multimedia Menggunakan Metode Inkuiri Terbimbing Untuk Meningkatkan Minat Dan Pemahaman Siswa. Pendidikan Fisika Indonesia Online Journal. 2016.

14. Sukiarko, E. Studi Di Kecamatan Tempuran Kabupaten Magelang The effect of Problem Based Training On Knowledge And Skills Of Nutrition Cadres In Posyandu activities A Study in Kecamatan Tempuran Kabupaten Magelang [Tesis]. Semarang. Universitas Diponegoro; 2007.

15. Hartati, D. Efektivitas Simulasi Monopoli Penilaian Status Gizi Balita Posyandu Untuk Meningkatkan Kemampuan Kaderdi Puskesmas Tegal Selatan Kota Tegal [Skripsi]. Semarang. Universitas Negeri Semarang; 2010.

16. Darmin, Y. Pengaruh Promosi Kesehatan dan Keselamatan Kerja Menggunakan Media Visual Terhadap Pengetahuan Dan Tindakan Pekerja Departemen Workshop Maintenance PT semen Bosowa Maros. [Tesis] Makassar: Universitas Hasanuddin; 2016.

\section{Submit your next manuscript to MPPKI}

- We accept pre-submission inquiries

- Our selector tool helps you to find the most relevant journal

- We provide round the clock customer support

- Convenient online submission

- Maximum visibility for your research

Submit your manuscript at

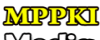

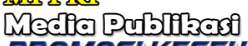

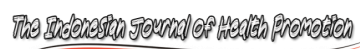

